\title{
AVALIAÇÃO DO DESENVOLVIMENTO AUDITIVO, DE LINGUAGEM E MOTOR EM LACTENTES
}

\author{
Júlia Roja Tavoni, Maria Cecília Marconi Pinheiro Lima
}

\begin{abstract}
Resumo
Introdução: Monitorar lactentes com indicadores de risco para perda auditiva justifica-se pela importância do diagnóstico precoce de possíveis alterações auditivas. O objetivo da pesquisa foi monitorar o desenvolvimento da função auditiva, da linguagem e das condições ambientais de lactentes que apresentam indicadores de risco para deficiência auditiva. Metodologia: Para avaliação do desenvolvimento auditivo utilizou-se avaliação auditiva comportamental. Quanto a avaliação do desenvolvimento da linguagem e de aspectos relacionados à motricidade orofacial, foi aplicada a Escala de Aquisições Iniciais da Linguagem e o Protocolo de Avaliação do Sistema Sensório Motor Oral. Para análise do desenvolvimento motor utilizou-se a Escala Affordances in the home environment for motor developmen).Os dados obtidos e as análises realizadas estão em consonância com a literatura e os lactentes, mesmo com indicadores de risco ao seu desenvolvimento e inseridos em ambientes não necessariamente favoráveis ao seu desenvolvimento, apresentaram um desenvolvimento compatível com sua faixa etária.
\end{abstract}

Palavras-chave: Lactente, Linguagem, Audição.

\section{Introdução}

Monitorar o desenvolvimento de lactentes com indicadores de risco para deficiência auditiva (IRDA) justifica-se pela importância do diagnóstico precoce de possíveis alterações. O Joint Committee on Infant Hearing $(\mathrm{JClH}, 2000)$ enfatiza que os bebês expostos a IRDA devem ter acompanhamento audiológico como garantia de intervenção precoce caso necessário. O objetivo deste projeto foi analisar o processo de desenvolvimento da função auditiva, da linguagem e das condições ambientais de lactentes que apresentam indicadores de risco para deficiência auditiva.

\section{Métodos}

Para avaliação do desenvolvimento auditivo, foi realizada avaliação auditiva comportamental e pesquisa do reflexo cócleo palpebral (RCP). Na avaliação do desenvolvimento da linguagem, utilizou-se o Protocolo de Avaliação do Sistema Sensório Motor Oral (PASSMO) e a Escala de Aquisições Iniciais da Linguagem (ELM). Por fim, para avaliação do desenvolvimento motor dos lactentes utilizou-se a Escala Affordances in the home environment for motor development (AHMED-IS). Essa pesquisa foi aprovada pelo Comitê de Ética em Pesquisas da Faculdade de Ciências Médicas/UNICAMP (número 808.875/14).

Os lactentes monitorados nasceram no CAISM, em boas condições de saúde e foram acompanhados aos 4, 8 e 12 meses de idade no Programa de Monitoramento Auditivo do Centro de Estudos e Pesquisas em Reabilitação (CEPRE).

\section{Resultados e Discussão}

Foram avaliados 27 lactentes, sendo que os IRDA's mais comuns foram: histórico familiar de deficiência auditiva congênita e uso de medicação ototóxica durante a gestação.

Nos testes de localização sonora, além de avaliar as habilidades da criança, foi possível mostrar aos pais de modo prático maneiras de beneficiar o desenvolvimento auditivo da criança. Barbosa et al (2016) afirmam que crianças sem resposta de localização de som entre 6 e 18 meses são 1,68 vezes mais propensas a ter alterações da linguagem entre 2 e 4 anos. Todos os lactentes apresentaram o RCP.

No monitoramento do desenvolvimento da linguagem, os resultados mostraram-se dentro dos parâmetros delimitados por cada protocolo, comprovando que indicadores de risco devem ser interpretados como relações probabilísticas (Almeida et al, 2012). Através do PASSMO, 51.85\% da amostra negou o uso de chupetas (aos 4 meses), fator positivo ao desenvolvimento do sistema estomatognático e para funcionalidade deste em relação à linguagem.

$\mathrm{Na}$ avaliação com o AHMED-IS, concluiu-se que $59.26 \%$ da amostra acompanhada está inserida em ambientes menos adequados em relação às possibilidades (affordances) de desenvolvimento. Tais dados coincidem com outras pesquisas, mostrando que crianças com IRDA muitas vezes encontram-se em ambientes que podem contribuir negativamente com seu desenvolvimento geral (Araujo et al, 2017).

\section{Conclusões}

O monitoramento do desenvolvimento da audição, de linguagem e motor de lactentes com IRDA's se mostra para as famílias como uma oportunidade de avaliação e acompanhamento do desenvolvimento do lactente. Além disso, esse acompanhamento propicia um momento de orientação acerca do desenvolvimento infantil, garantindo melhores possibilidades de desenvolvimento à criança.

ALMEIDA,C.G.M de; RODRIGUES, O. M. P. R.;SALGADO, M. H. Diferenças no desenvolvimento de meninos e meninas em condições de risco. Boletim de Psicologia, v. 62, n. 136, p. 1-14, 2012

ARAUJO, D. M. et al. Development of infants with hearing impairment risk indicators and the environment classification. J Hum Growth Dev, v. 27, n. 1 , p.48-54, 2017

BARBOSA LAUREANO LUIZ, C. et al. Relação entre as habilidades auditivas no primeiro ano de vida e o diagnóstico de linguagem em prematuros. Revista CEFAC, v. 18, n. 6, 2016.

Joint Committee on Infant Hearing. Year 2000 position statement: principles and guidelines for early hearing detection and intervention programs. Audiology Today, Special Issue, Reston, VA.: A.A.A, 2000 